\title{
Editorial
}

\section{A letter from the Editor}

\section{Dear Colleague,}

On the threshold of 1991 it is a pleasure to write this letter to you with a warm wish for a Happy New Year. All of us at the Editorial Office in Uppsala look forward to another year of stimulating collaboration both with you and the authors, the referees and the Editorial Board of Diabetologia. We sincerely hope to present you with a journal filled with science of the highest quality, which will stimulate new research in diabetology and lead to innovations in the care of diabetic patients.

Looking back at 1990 the key issue for the journal was the proposal to the General Assembly at the 26th meeting of the EASD in Copenhagen that a subscription to Diabetologia should be included in the EASD membership fee. A similar proposal has previously been made several times but has always been vetoed for one reason or another. This time the scheme contained the proviso that the total cost of the subscription plus the membershipfee should not be allowed to exceed $£ 70$. A solidarity fund should furthermore be created to ensure that Eastern European members and younger colleagues receive financial support to cover the extra cost of subscription. A great majority of those present at the General Assembly voted in favour of the proposal which will hopefully be launched from January 1992 . As a result of the considerably increased circulation of Diabetologia it is hoped that we will be able tonegotiate an expansion of the journal page number by at least $30 \%$. Each issue of the journal going to EASD members will also contain a News Letter with information of specific interest to the membership. By this means we hope to provide each member with immediate access to the most upto-date coverage of worldwide progress in diabetology. All members will thus also have access to a reference library of their own in order to be able to quickly refer back to vital pieces of information. At the Editorial Office we feel that this new arrangement is a great step forward for Diabetologia and also increases our responsibility to produce a journal of the highest possible standard.

The past year has been a good year for Diabetologia in other respects. The inflow of manuscripts has been intense and, as for 1989 , remains at over 475 . The journal is highly cited as evidenced by an impact score of 3.8 which gives us a rank of number eight on the list of the 52 most cited jour- nals in endocrinology and metabolism. Despite the gratifying impact score we have a very restricted space for publication and with the present high inflow of manuscripts there is considerable competition for this space. Submitted manuscripts therefore have to be ranked according to a strict priority system which can cause consternation to the authors. As for all prestigious scientific journals the editorial policy is to select in the first place those manuscripts which show the most prominent scientific qualities and provide the highest degree of novelty and conceptual advance. For reasons of publication time the number of accepted manuscripts must, however, remain limited. This of necessity means that some manuscripts which have received favourable reviews and are of a generally good standard have to be rejected. Although the final decision on each manuscript is always made by the Editor-in-Chief, decisions to reject even good manuscripts are often taken after considerable discussion at our local Editorial Conference which is held once every second week. In these cases, and they are not uncommon, I can certainly attest that the editor feels sad not to be able to accept an otherwise good paper for publication and fully understands the frustrations expressed by some authors. We try to formulate the editorial decision letter so that the authors may understand this dilemma and can submit a revised version to another suitable journal. We believe that the careful comments made by our referees can almost always serve to improve even good manuscripts.

Although our present rejection rate of close to seventy-five per cent is too high I regard the considerable inflow of manuscripts as a sign of good health of the journal and hope it will continue. We on our side will do our best to negotiate an expansion of the number of pages in Diabetologia in order to be able to raise the acceptance rate. All of us look forward to offering our readers continuous coverage of the most recent and relevant progress in diabetology with the goal of providing every reader of Diabetologia with as many exciting articles as possible each month.

Again, all good wishes for the coming year,

Sincerely yours, Claes Hellerström Uppsala, 1 January 1991 